\title{
A case report of revision occipital-cervical fusion after atlanto-axial instrumentation failure for neurofibromatosis type I
}

\author{
Hayato Kinoshita ${ }^{1 *}$, Naohisa Miyakoshi ${ }^{2}$,Takashi Kobayashi', Toshiki Abe ${ }^{1}$, Kazuma Kikuchi ${ }^{1}$ and Yoichi Shimada ${ }^{2}$
}

\begin{abstract}
Background: Neurofibromatosis type 1 is an autosomal dominant genetic disease with characteristic café-au-lait spots, neurofibroma, and dystrophic changes in the bones. However, complications involving atlanto-axial dislocation are rare.

Case presentation: We report a case of neurofibromatosis with atlanto-axial dislocation. The chief complaints were numbness of the upper limb and gait disturbance. We performed short fusion using the Brooks method. However, recurrence of the dislocation was found after 5 months recovery, and the patient underwent posterior fusion from the occipital bone to C4. Thereafter, she had a good postoperative course.

Conclusions: Neurofibromatosis patients often exhibit a low bone mineral density because of dystrophic changes, and are prone to fragile bones. In the present case, the use of long fusion at the first surgery may have helped to form a strong fusion of fragile bone.
\end{abstract}

Keywords: Cervical spine, Neurofibromatosis type 1, Long fusion

\section{Background}

Neurofibromatosis type 1 (NF1) is an autosomal dominant disease, which is defined by the National Institute of Health as presenting with café-au-lait spots, neurofibroma, freckling of the axillary or inguinal region, glioma of the optic nerve, dystrophic bone disease, or family history [1]. The dystrophic changes of the bones involve rib penciling, scalloping of the vertebral body, costotransverse spindling, increased width between each pedicle, and expansion of the foramina. In a study of 102 patients with neurofibromatosis, patients with dystrophic changes (defined as dystrophic type) exhibited a rapid progression of spinal deformities, while conservative treatments were ineffective [2]. Kawabata et al. also reported an incidence of spinal deformity of 10-69\% in neurofibromatosis patients [3], while Yong-Hing et al. reported cervical spine deformity in 17 of 56 neurofibromatosis patients (approximately 30\%) [4]. However, the complication of atlantoaxial dislocation (AAD) is rare in cervical spine deformity,

\footnotetext{
* Correspondence: hayato@med.akita-u.ac.jp

${ }^{1}$ Akita Kosei Medical Center, 1-1-1 Nishibukuro lijima, Akita 011-0948, Japan Full list of author information is available at the end of the article
}

with only seven cases previously reported [5-9]. Herein, we report a case requiring two cervical spine surgeries because of recurring AAD.

\section{Case presentation}

A 40-year-old woman consulted us with multiple café-au-lait spots, family history of neurofibromatosis, and prior diagnosis of NF1 by her primary doctor. Her chief complaints were numbness of the upper limb and gait disturbance from 1 month prior. Neurological examination revealed a spastic gait. The Romberg test was positive. The one leg standing test showed instability in both legs. Hyperreflexia showed a deep tendon of the biceps, triceps, patella, and Achilles on both sides. In the manual muscle test, only finger extension was reduced to 4 on the left hand. The sense of pain was reduced on the right side of her body.

Radiography showed expansion of the atlanto-dental interval at the neutral position of the cervical spine (Fig. 1a), while canal stenosis was observed by computed tomography and magnetic resonance imaging (Fig. 1b, c, e). An abnormality of the left side vertebral artery inside of the $\mathrm{C} 1$ lamina was observed by computed tomographic 

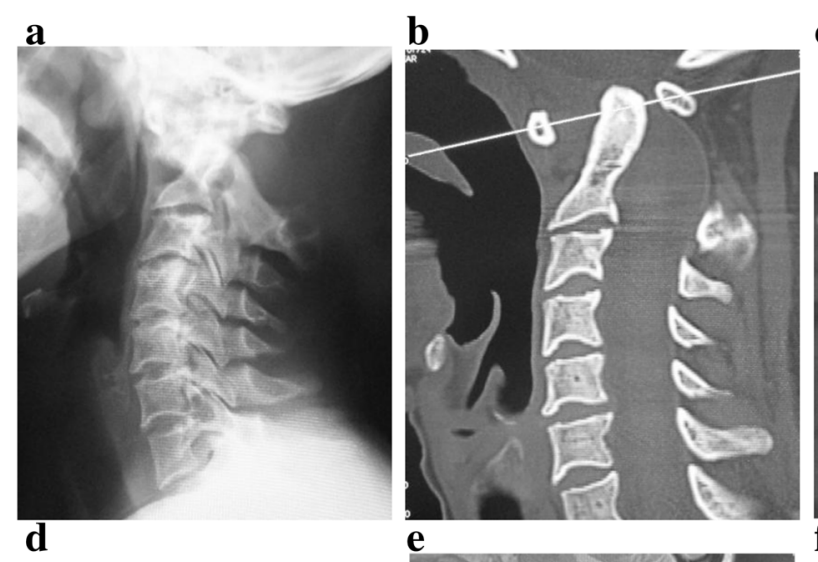

c
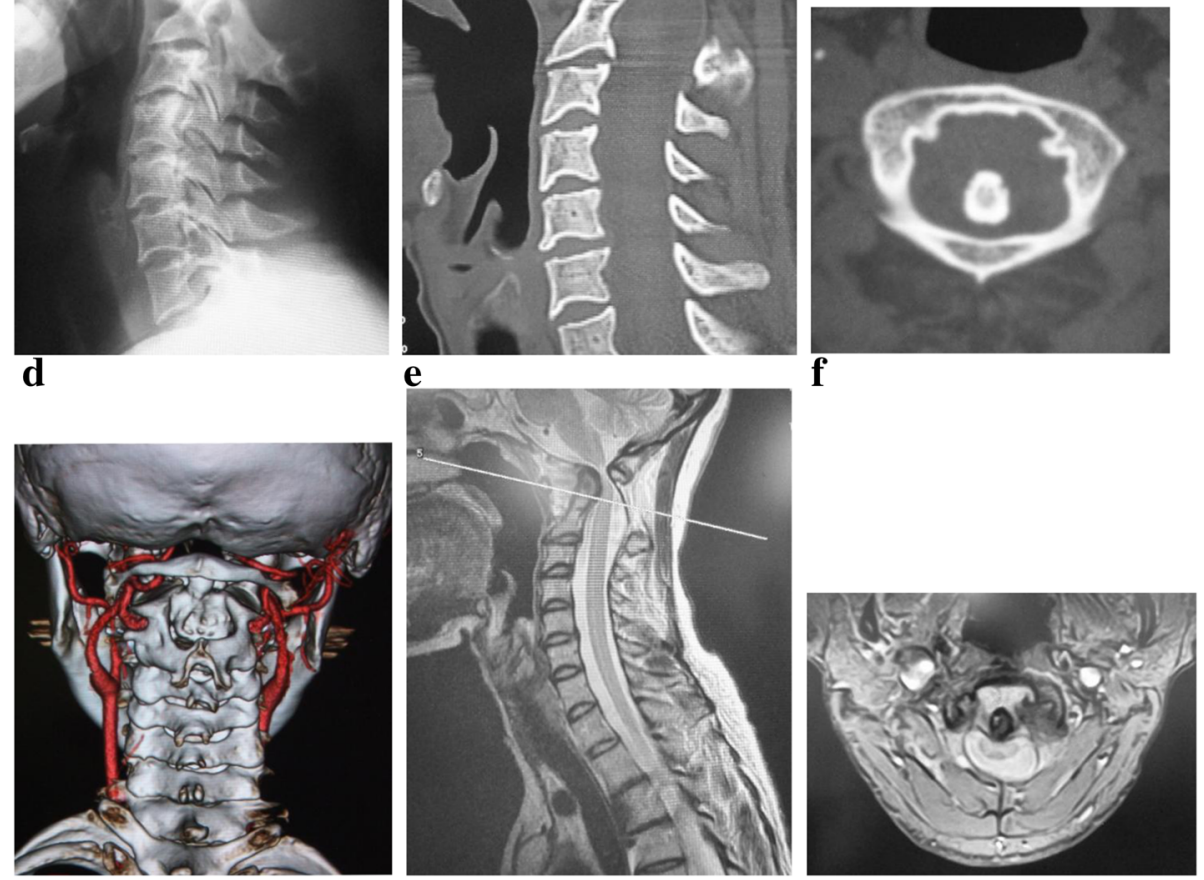

Fig. 1 Preoperative imaging. a The cervical neural position showing expansion of the atlanto-dental interval. The upper atlantodental interval was $11.8 \mathrm{~mm}$. b Computed tomography showing enlargement of the C2/3 foramen on the sagittal side of the left cervical spine. c Axial computed tomography image at the height of the C2 vertebra showing enlargement of the left side C2/3 foramen. $\mathbf{d}$ Computed tomographic angiography showing a left-side vertebral artery inside of the C1 lamina. e T2-weighted magnetic resonance imaging of the sagittal cervical spine showing spinal cord compression caused by a dislocated odontoid. f T2-weighted magnetic resonance cervical axial imaging showing disruption of the transverse ligament of the atlas and neurofibroma between the anterior arch of $\mathrm{C} 1$ and the odontoid

angiography (Fig. 1d). Magnetic resonance imaging showed dural ectasia from $\mathrm{C} 2$ to $\mathrm{T} 2$, and AAD. There was no neurofibroma between the atlas and the odontoid (Fig. 1e, f).

We performed surgery to prevent the progression of myelopathy caused by AAD. We initially planned a long posterior fixation. However, we achieved a good closed reduction of the AAD under general anesthesia. Thus, we tied an ultra-high molecular weight polyethylene cable (Nesplon; Alfresa, Inc., Osaka, Japan) to the C1 lamina and spinous process of $\mathrm{C} 2$ to maintain the position of the reduced AAD. Furthermore, we tied two nesplon cables $^{\oplus}$ to the sublamina of $\mathrm{C} 1$ and $\mathrm{C} 2$ according to the Brooks technique. The iliac bone was grafted on between the $\mathrm{C} 1$ and $\mathrm{C} 2$ laminae (Fig. 2). The operative time was $1 \mathrm{~h} 35 \mathrm{~min}$, and bleeding was $<50 \mathrm{ml}$. After the operation, the patient showed improvement of neurological symptoms. She wore a Philadelphia brace continuously. However, at 5 months after surgery she felt neck pain and consulted us again. Computed tomography showed fracture of the $\mathrm{C} 1$ lamina and recurrence of AAD (Fig. 3).
We reoperated using a long posterior fusion. Because of the existing abnormal vertebral artery inside of the $\mathrm{C} 1$ lamina, we gently removed scar tissue using a subperiosteal approach, and revealed the $\mathrm{C} 1 / 2$ facet under direct vision. We then introduced two intra-articular titanium spacers (KiSCO, Kobe, Japan) for fixed bilateral atlanto-axial joints.

Vertex select ${ }^{\oplus}$ (Medtronic, Minneapolis, MN, USA), a plating system for occipital bone, was used for posterior fixation of the occipital bone and cervical spine. Facet screw fixations were inserted on the right side of $\mathrm{C} 2 / 3$ and both sides of C3/4. Lateral mass screw fixation was performed on both sides of $\mathrm{C} 4$. Two pre-bending rods were connected to these screws on both sides of the cervical spine, and two rod couplers were connected to the pre-bending rods at the height of $\mathrm{C} 2$ and $\mathrm{C} 4$. To avoid stress concentration and refractures, sublaminar taping was performed at $\mathrm{C} 2, \mathrm{C} 3$, and $\mathrm{C} 4$ using nesplon cables $^{\oplus}$. Finally, her right side iliac bone was grafted between the occipital bone and the back of the C1 lamina using the Newman technique (Fig. 4a, b). The operative time was $3 \mathrm{~h} 56 \mathrm{~min}$, and bleeding was $425 \mathrm{ml}$. She wore 

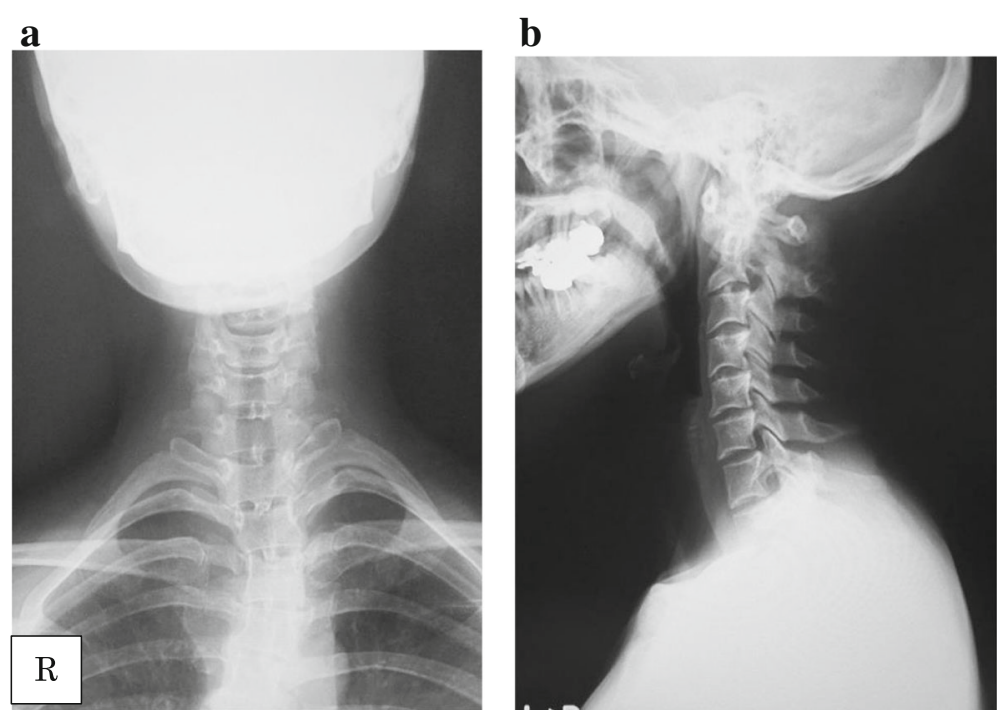

Fig. 2 First operation. a Anterior-posterior radiography image at the first operation. b Sagittal radiography imaging at the first operation. The taping system and the iliac bone were used for fixation between $\mathrm{C} 1$ and C2. The upper atlantodental interval was $3.5 \mathrm{~mm}$

a Philadelphia brace for 1 year after the second operation. At 4-year follow up, there was no AAD recurrence (Fig. 4c, d) and her neck pain had improved. She could walk independently, and a manual muscle test showed 'normal' for every muscle.

\section{Discussion and conclusions}

AAD is a rare complication in neurofibromatosis patients. As a potential cause of AAD, Isu et al. reported that one of three neurofibromatosis patients with AAD had a neurofibroma between the anterior arch of $\mathrm{C} 1$ and the odontoid [7]. Craig et al. also reported one patient with neurofibromatosis requiring cervical spine surgery with AAD caused by disruption of the transverse ligament of atlas [8]. Furthermore, Hasegawa et al. suggested that AAD was caused by either abnormal development or neoplastic destruction of the joint [9]. In the present case, AAD was caused by disruption of the transverse ligament of atlas (Fig. 1f). In these four reported AAD cases, one case received laminectomy of $\mathrm{C} 1$, posterior fusion from the occipital bone to $\mathrm{C} 3$, and anterior fusion from $\mathrm{C} 2$ to $\mathrm{C} 5$; one case received posterior decompression of both the foramen magnum and $\mathrm{C} 1$, and posterior fusion from the occipital bone to $\mathrm{C} 3$; one case with neurofibromatosis between the odontoid and the anterior arch of $\mathrm{C} 1$ received removal of the anterior arch of atlas and odontoid displacement via a trans-oral approach, and C1-2 fusion; while one case used the Brooks technique [7, 8]. Importantly, all cases showed good outcomes. For postoperative treatment, external fixation was reported to maintain the correction and obtain solid bone union [10].
In the present case, we used the Brooks method, as previously reported [8], and used a neck collar for external fixation. We also used a nesplon cable $e^{\bullet}$ to fix the atlas and the axis. Fujita et al. showed that use of stainless steel wire or the nesplon cable $^{\bullet}$ for sublaminar fixation provided equal stability [11]. Hamasaki et al. also reported that pedicle screw augmentation with a sublaminar nesplon cable ${ }^{\bullet}$ provided firmer fixation than pedicle screw augmentation only in the osteoporotic human thoracolumbar spine [12]. Furthermore, Saito et al. demonstrated no surgical complications such as lamina fracture in 44 patients with atlanto-axial subluxation who received the modified Brooks technique using ultra-high molecular weight polyethylene cable [13]. However, there are no reports on the use of nesplon cable $^{\circ}$ in NF1 patients. Of note, AAD recurred in our patient. Thus, further studies are required to confirm the utility of the nesplon cable ${ }^{\circ}$ in NF1 patients with AAD.

Ito et al. compared the outcomes of 48 patients receiving posterior wiring using the McGraw or Brooks techniques with 28 patients receiving transarticular screw fixations using the Magarl technique [14], and found that nine of the 48 wiring patients did not obtain bone union, four of whom showed recurrence of atlantoaxial subluxation, while all patients receiving the Magarl technique obtained bone union. The authors suggested that even if posterior wiring was performed in AAD patients, sufficient postoperative rest periods and external fixation (e.g., Halo) would provide the best bone union and prevent recurrence of atlantoaxial subluxation. Our case wore a Philadelphia brace continuously after the first operation, but AAD recurrence occurred. 

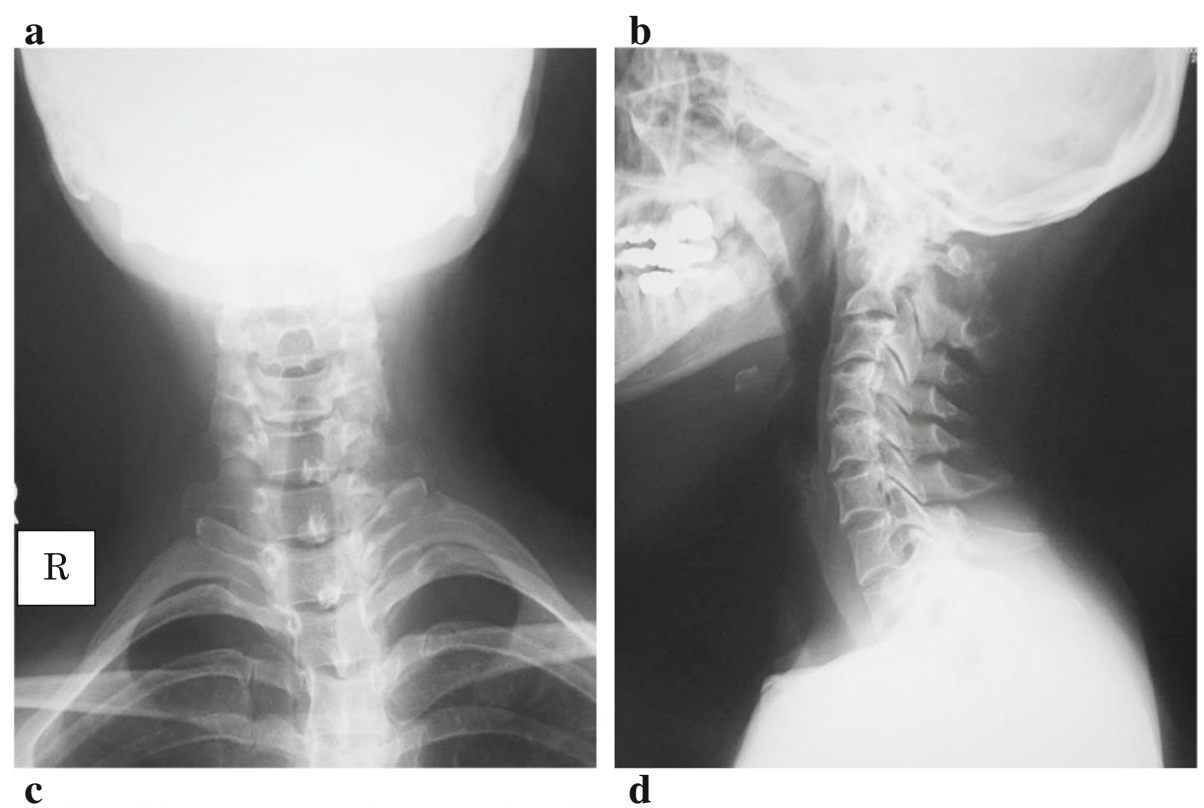

c

d
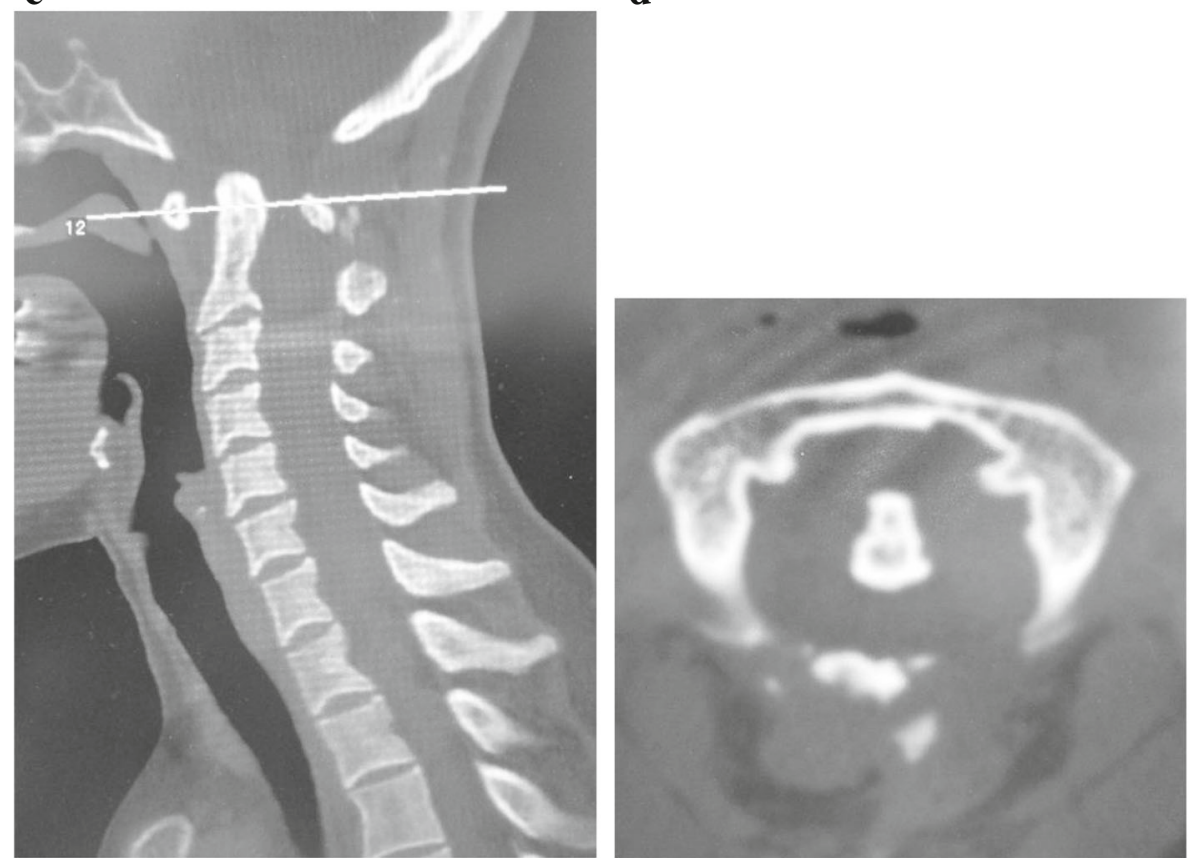

Fig. 3 Recurrence of atlanto-axial dislocation. a Anterior-posterior radiography image. b Sagittal radiography imaging. The upper atlantodental interval was $8.5 \mathrm{~mm}$. c Computed tomography sagittal image showing the recurrence of the atlanto-axial dislocation. $\mathbf{d}$ Computed tomography axial image showing the fracture of the C1 lamina

Thus, it may have been useful to perform transarticular screw fixation (e.g., using the Magarl technique) at the first surgery, taking care to look for abnormal vertebral arteries. It is also important to note that there are potential disadvantages when using cables for $\mathrm{C} 1-2$ fixation. For example, Yoshimoto et al. reported that C1-2 fixation in a hyperlordotic position caused subaxial kyphosis after surgery, and progression of kyphosis occasionally caused additional myelopathy [15].
In the present case, we performed a second surgery using intra-articular spacers with a long fixation from the occipital bone to $\mathrm{C} 4$. Tokuhashi et al. reported the efficacy of C1-2 intra-articular screw fixation for atlanto-axial subluxation, including no changes in the atlas-dens interval during follow-up, no impairment of walking ability, and no surgery-related complications in rheumatoid arthritis patients [16]. Similarly, our case showed improvement in preoperative symptoms and no 

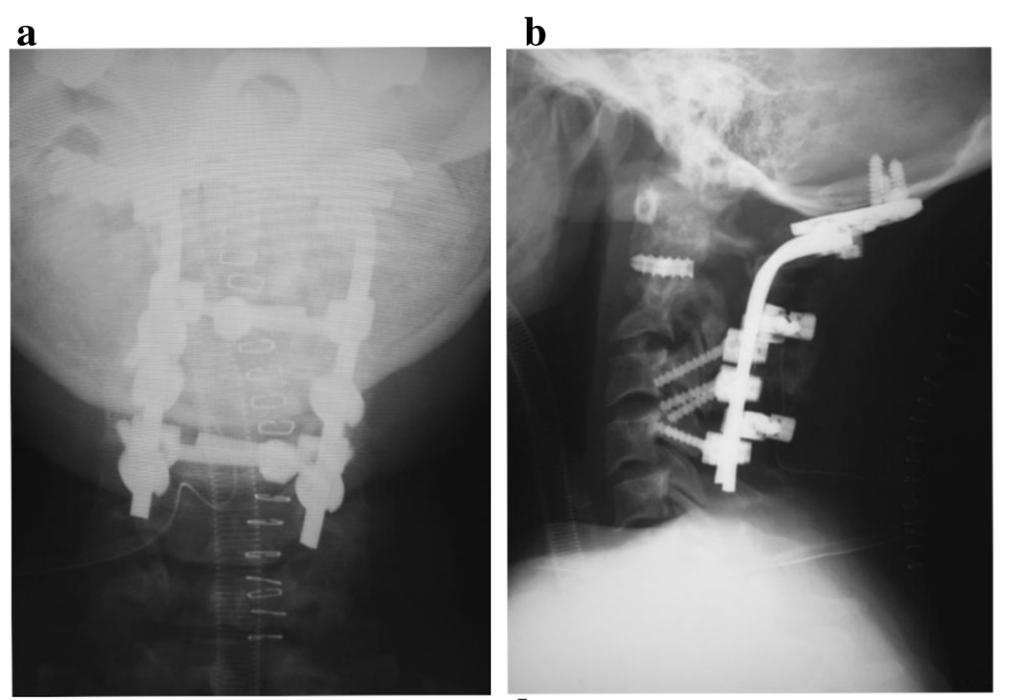

c

d
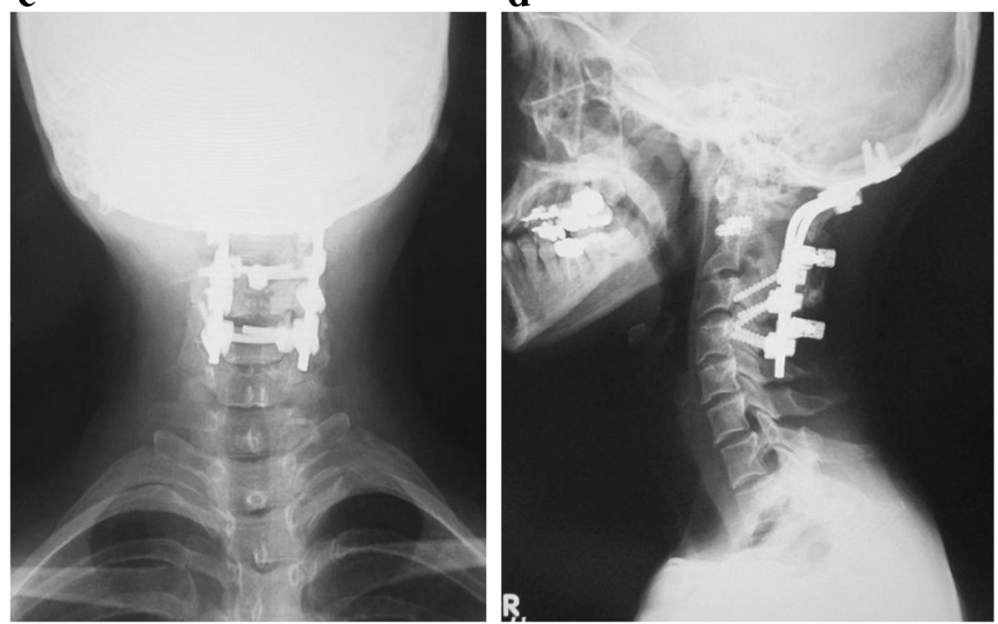

Fig. 4 Second operation. a The anterior-posterior radiography image at the second operation. b Sagittal radiography image at the second operation. A long fixation from the occipital bone to C4 was performed. The upper atlantodental interval was $2.8 \mathrm{~mm}$. c Anterior-posterior radiography image at 4 years after the second operation. $\mathbf{d}$ Sagittal radiography image at 4 years after the second operation

AAD recurrence. We suggest that the secondary AAD in our case was caused by fracture of the C1 lamina (Fig. 3), rather than rupture of the C1-2 fixation site. The only obvious dystrophic change in our case was expansion of the left $\mathrm{C} 2 / 3$ foramina, with no evidence of other dystrophic changes such as rib penciling, scalloping of the vertebral body, costotransverse spindling, or increased width between each pedicle. Furthermore, there was no evidence of the rapid progressive spinal deformities reported in dystrophic type neurofibromatosis [2]. Thus, we suggest that the fracture of the $\mathrm{C} 1$ lamina in our case was not caused by rapid spinal deformity. Stevenson et al. reported decreased bone mineral density in children and adolescents with NF1, with or without skeletal abnormalities, compared with controls [17]. Lammert et al. also reported a marked decrease in bone mineral density of NF1 patients who required surgical treatment of scoliosis
[18]. Based on these reports, the selection of a long rigid fixation because of potential bone fragility may have prevented the secondary AAD in our case.

\section{Abbreviations}

AAD: Atlanto-axial dislocation; NF1: Neurofibromatosis type 1

\section{Acknowledgments}

We thank Edanz Group (http://www.edanzediting.com) for editing a draft of this manuscript.

\section{Funding}

Not applicable.

\section{Availability of data and materials}

The data supporting the findings of this study are available within the article.

\section{Authors' contributions}

KT performed the surgery. HK, TK, TA, and KK prepared the manuscript. NM and YS assisted in drafting and review of the manuscript. All authors read and approved the final manuscript. 


\section{Ethics approval and consent to participate}

Not applicable.

\section{Consent for publication}

Written informed consent was obtained from the patient for publication of this case report and the accompanying images.

\section{Competing interests}

The authors declare that they have no competing interests.

\section{Publisher's Note}

Springer Nature remains neutral with regard to jurisdictional claims in published maps and institutional affiliations.

\section{Author details}

'Akita Kosei Medical Center, 1-1-1 Nishibukuro lijima, Akita 011-0948, Japan. ${ }^{2}$ Department of Orthopedic Surgery, Akita University Graduate School of Medicine, 1-1-1 Hondo, Akita 010-8543, Japan.

Received: 8 September 2018 Accepted: 4 April 2019

Published online: 25 April 2019

\section{References}

1. Nerofibromatosis. Conference statement. National Institutes of Health consensus development conference. Arch Neurol. 1988. https://doi.org/10. 1001/archneur.1988.00520290115023.

2. Winter RB, Moe JH, Bradford DS, Lonstein JE, Pedras CV, Weber AH. Spine deformity in neurofibromatosis. A review of one hundred and two patients. J Bone Joint Surg Am. 1979;61(5):677-94.

3. Kawabata S, Watanabe K, Osogane N, Ishii K, Nakamura M, Toyama Y, Matsumoto M. Surgical correction of severe cervical kyphosis in patients with neurofibromatosis type 1. J Neurosurg Spine. 2013. https://doi.org/10 3171/2012.11.SPINE12417.

4. Yong-Hing K, Kalamchi A, MacEwen GD. Cervical spine abnormalities in neurofibromatosis. J Bone Joint Surg Am. 1979;61(5):695-9.

5. Veras LM, Castellanos J, Ramírez G, Valer A, Casamitjana J, González F. Atlanto axial instability due to neurofibromatosis: case report. Acta Orthop Belg. 2000;66(4):392-6.

6. Maheshwari S, Kale HA, Desai SB, Kohli A. Magnetic resonance imaging findings in an unusual case of atlanto axial dislocation and vertebral arteryvein fistulas in a patient of neurofibromatosis-1. Australas Radiol. 2002;46(3): 316-8.

7. Isu T, Miyasaka K, Abe H, Ito T, Iwasaki Y, Tsuru M, Kitaoka K, Tsunoda M. Atlantoaxial dislocation associated with neurofibromatosis. J Neurosurg. 1983. https://doi.org/10.3171/jns.1983.58.3.0451.

8. Craig JB, Govender S. Neurofibromatosis of the cervical spine. A report of eight cases. J Bone Joint Surg Br. 1992;74(4):575-8.

9. Hasegawa H, Bitoh S, Katoh A, Tamura K. Bilateral vertebral arteriovenous fistulas and atlantoaxial dislocation associated with neurofibromatosis -case report-. Neurol Med Chir (Tokyo) 1989. https://www.jstage.jst.go.jp/article/ nmc1959/29/1/29_1_55/_pdf/-char/en. Accessed 14 July 1989.

10. Wang Z, Liu Y. Research update and recent developments in the management of scoliosis in neurofibromatosis type 1. Orthopedics. 2010. https://doi.org/10.3928/01477447-20100329-20

11. Fujita M, Diab M, Xu Z, Puttlitz CM. A biomechanical analysis of sublaminar and subtransverse process fixation using metal wires and polyethylene cables. Spine. 2006. https://doi.org/10.1097/01.brs.0000232831.63589.22.

12. Hamasaki T, Tanaka N, Kim J, Okada M, Ochi M, Hutton WC. Pedicle screw augmentation with polyethylene tape: a biomechanical study in the osteoporotic thoracolumbar spine. J Spinal Disord Tech. 2010. https://doi. org/10.1097/BSD.0b013e31819942cd.

13. Saito R, Hase H, Mikami Y, Tsuji Y, Ikeda T, Osawa T, Hayashida T, Kubo T. Clinical study of modified brooks technique for atlanto-axial subluxation using polyethylene tape. J Spinal Disord Tech. 2006;19(1):11-7.

14. Ito T, Hayashi M, Ohshima Y. Surgical treatment of atlantoaxial subluxation by posterior arthrodesis. Spinal Surgery. 1997;11(2):151-8 https://www. jstage.jst.go.jp/article/spinalsurg/11/2/11_KJ00003710530/_pdf/-char/ja.

15. Yoshimoto $H$, Ito M, Abumi K, Kotani Y, Shono Y, Takada T, Minami A. A retrospective radiographic analysis of subaxial sagittal alignment after posterior C1-C2 fusion. Spine (Phila Pa 1976). 2004;29(2):175-81.
16. Tokuhashi Y, Ajiro Y, Oshima M, Umezawa N. C1-C2 intra-articular screw fixation for atlantoaxial subluxation due to rheumatoid arthritis. Orthopedics. 2009;32(3):172.

17. Stevenson DA, Moyer-Mileur LJ, Murray M, Slater H, Sheng X, Carey JC, Dube $\mathrm{B}$, Viskochil DH. Bone mineral density in children and adolescents with neurofibromatosis type 1. J Pediatr. 2007. https://doi.org/10.1016/j. jpeds.2006.10.048

18. Lammert M, Kappler M, Mautner VF, Lammert K, Störkel S, Friedman JM, Atkins D. Decreased bone mineral density in patients with neurofibromatosis 1. Osteoporos Int. 2005. https://doi.org/10.1007/s00198-005-1940-2.

\section{Ready to submit your research? Choose BMC and benefit from:}

- fast, convenient online submission

- thorough peer review by experienced researchers in your field

- rapid publication on acceptance

- support for research data, including large and complex data types

- gold Open Access which fosters wider collaboration and increased citations

- maximum visibility for your research: over $100 \mathrm{M}$ website views per year

At $\mathrm{BMC}$, research is always in progress.

Learn more biomedcentral.com/submissions 